\title{
Research on the Risk Evaluation of Mining Land Collapse in Mentougou Region
}

\author{
Zhuoyan Liu, a, Yongbo Teng ${ }^{1, b}$, Tianlu Yao ${ }^{1, c}$ Naiqi Shen ${ }^{1, d}$ \\ ${ }^{1}$ School of Engineering and Technology, China University of Geosciences, Beijing, 100083, China \\ aLiuzhuoyan@sina.com, bybteng@126.com, ctlyao@126.com, ${ }^{d}$ nqshen@cugb.edu.cn
}

\begin{abstract}
Keywords: mining land collapse, hazard, vulnerability, risk evaluation
Abstract. Risk evaluation involves not only the natural characteristic of hazard, but also the socioeconomic properties of the vulnerability. Therefore risk evaluation is a complicated but important scientific problem. According to the analysis of the developed characteristic, forming condition and influent factors of the mining collapse in Mentougou region, Beijing, this paper provides the index system and evaluation methods based on hazard degree and vulnerability degree. And the risk degree is classified to 5 grades. Based on these methods, the land collapse risk in Mentougou region has evaluated, and then the map of the risk grades has drawn. The evaluation result can almost reflect the actual situation and be a foundation of the collapse controlling work in this region.
\end{abstract}

\section{Introduction}

United Nations Humanitarianism Affair defined the risk that it is the expected loss of lives, properties and economic activity caused by special hazard in some area or some time. The expression of the risk evaluation is represented as: $\operatorname{Risk}(R)=$ hazard $(H) \times$ vulnerability $(V)$. This expresses that the value of risk degree obtained by the product of hazard and vulnerability. The value scope of these three factors is $0 \sim 1$ or $0 \% \sim 100 \%$. The risk definition and calculation equation given by the United States were recognized and applied by many scholars and some institutions.

Risk of mining land collapse is composed of hazard and vulnerability. The hazard degree is the forming possibility, which is the nature property of risk. The hazard degree is random and uncertain, which makes people can't predict it precisely and control it totally. The vulnerability is the social property of risk, which means the resistance and recovery ability of the human and economic activity in the disaster area. The human and economic activity are including population density, residence environment, density of property value, property type, richness of the resources and vulnerability of environment. Risk evaluation of mining land collapse is based on the hazard evaluation and vulnerability evaluation. The risk reflects the nature property (hazard degree of something occurring disaster) and the social property (economic vulnerability of the disaster area) [1].

Mentougou region is the major coal base in Beijing. In terms of the hundreds of years' the mine exploiting, the goaf is widely underground and collapse occurs frequently over ground. The collapse disaster caused great harm to local residents and economic construction. The developed characteristic, forming condition, activate rule and influent factors of the collapse in this region are invested and studied these years. Purpose of this paper is to establish the index system and the evaluation method of collapse risk and provide scientific basis for the collapse hazard prevention in Mentougou region.

\section{Hazard evaluation method of the mining land collapse}

Main contents of the risk evaluation is to evaluate the activate degree of land collapse on different goafs. Therefore, the result can reflects the destructive power of the collapse underground[2,3]. The basic method is to divide the map to many elements firstly. Then the evaluation indexes and weight are determined. After these things, the hazard degree of each element can be calculated. Finally, the hazard zoning can be carried out based on the distribution situation of regional hazard. 
Selection and classification of hazard evaluation index. The evaluation indexes of mining land collapse in Mentougou region include historical disaster indexes and potential disaster indexes. Combined the research of mining land collapse in Beijing mountains previously, collapse density, collapse area percentage, geological structure, capping rock type, coal thickness, goaf percentage and mining management are chosen as the evaluation indexes.

According to current situation and studying level of the mining land collapse in Mentougou area, the hazard is divided to 5 grades, which is no hazard (I), low hazard (II), medium hazard (III), less high hazard (IV) and high hazard (V). The division standards of each index are shown in table 1.

Table 1 Hazard evaluating index and classification

\begin{tabular}{llllll}
\hline \multirow{2}{*}{ Index } & \multicolumn{5}{c}{ Classification } \\
\cline { 2 - 6 } $\begin{array}{l}\text { Collapse density } \\
/ \mathrm{km}^{2}\end{array}$ & No (I) & Low (II) & Medium (III) & Less high (IV) & High (V) \\
\hline $\begin{array}{l}\text { Collapse area } \\
\text { Percentage } / \%\end{array}$ & 0 & $<0.5$ & $0.5 \sim 1.5$ & $1.5 \sim 2.5$ & $>2.5$ \\
\hline $\begin{array}{l}\text { Geological } \\
\text { structure }\end{array}$ & $\begin{array}{l}\text { No developing, } \\
\text { with no or less } \\
\text { small faults }\end{array}$ & $\begin{array}{l}\text { No developing, } \\
\text { with some small } \\
\text { faults }\end{array}$ & $\begin{array}{l}\text { More developed, } \\
\text { with trunk faults }\end{array}$ & $\begin{array}{l}\text { Developed, with } \\
\text { large faulted-zone, } \\
\text { and big density }\end{array}$ & $\begin{array}{l}\text { Developed huge } \\
\text { faulted-zone, with } \\
\text { dense faulted-zone }\end{array}$ \\
\hline Capping rock type & $\begin{array}{l}\text { Hard massive } \\
\text { medium } \\
\text { bedded }\end{array}$ & $\begin{array}{l}\text { Hard medium } \\
\text { bedded } \\
\text { fragmentary rock }\end{array}$ & $\begin{array}{l}\text { Layered } \\
\text { fragmentary rock }\end{array}$ & $\begin{array}{l}\text { Soft fragmentary } \\
\text { rock, clay Stone, } \\
\text { shale, } \\
\text { volcaniclastic rock }\end{array}$ & $\begin{array}{l}\text { Anthrinoid siltstone, } \\
\text { Anthrinoid shale, } \\
\text { quaternary loose } \\
\text { gravel, sand soil, silt }\end{array}$ \\
\hline Coal thickness $/ \mathrm{m}$ & $>50$ & $35 \sim 50$ & $35 \sim 25$ & $25 \sim 15$ & $<15$ \\
\hline Goaf percentage/\% & $>0.5$ & $0.5 \sim 5$ & $5 \sim 15$ & $15 \sim 25$ & $>25$ \\
\hline $\begin{array}{l}\text { Mining } \\
\text { management }\end{array}$ & $\begin{array}{l}\text { Following the } \\
\text { standards most } \\
\text { strictly }\end{array}$ & $\begin{array}{l}\text { Following the } \\
\text { standards } \\
\text { more strictly }\end{array}$ & $\begin{array}{l}\text { Following the } \\
\text { standards } \\
\text { basically }\end{array}$ & $\begin{array}{l}\text { Not following the } \\
\text { standards }\end{array}$ & $\begin{array}{l}\text { Digging } \\
\text { excessively }\end{array}$ \\
\hline Grade value & 0 & 1 & 3 & 6 & 9 \\
\hline
\end{tabular}

Determination of the weight. The mining land collapse is caused by many factors. The intensity of collapse is variant in different geological environment and mining condition. This paper uses relativity analysis method to fix the weight of each index. The collapse density and collapse area percentage are the main factors, and other indexes are the relativity factors. After relativity analysis, the weight of each index can be calculated. The weight vector is $R=\left(R_{1}, R_{2}, \ldots, R_{7}\right)=(0.493,0.507$, 0.193, 0.196, 0.199, 0.208, 0.204).

Calculation method and classification of hazard degree. The hazard degree can be expressed by hazard exponent. The forming possibility of disaster gets bigger as the exponent gets bigger. Hazard exponent is calculated by the equation:

$$
W=\sum_{k=1}^{n} d(k) \sum_{j=1}^{m} R(j) \cdot X(i, j)
$$

In eqn. $1: W$ is the hazard exponent of each element; $\mathrm{n}$ is the type of historical disaster or potential disaster; $d(k)$ is the weight of each type, the value is 0.4 or 0.6 ; $\mathrm{m}$ is number of indexes; $R(j)$ is the weight of each index; $X(i, j)$ is the value of measured data after classified by table 1 .

This paper chooses 30 typical collapse spots in Beijing to evaluate. The classification standards of mining collapse can be obtained. The standards are shown in table 2.

Table 2 Hazard grading standards

\begin{tabular}{llllll}
\hline Hazard grade & No (I) & Low (II) & Medium (III) & Less high (IV) & High (V) \\
\hline Hazard exponent & $<2.0$ & $2.0 \sim 3.0$ & $3.0 \sim 4.0$ & $4.0 \sim 5.0$ & $>5.0$ \\
\hline
\end{tabular}

\section{Vulnerability evaluation of the mining land collapse}

Selection and classification of vulnerability evaluation index. Vulnerability reflects the sensibility of the social economic to disaster, which is directly related to the consequence of disaster[1]. According to the economic condition in the collapse disaster area, the 11 parameters are chosen as evaluation indexes. The division standards of each index are shown in table 3. 
Table 3 Vulnerability evaluating index and classification

\begin{tabular}{lllll}
\hline \multirow{2}{*}{ Index } & \multicolumn{4}{c}{ Classification } \\
\cline { 2 - 5 } & Low $(\mathrm{I})$ & Medium $(\mathrm{II})$ & Less high $(\mathrm{III})$ & High (IV) \\
\hline Population density $/ \mathrm{km}^{2}$ & $<10$ & $10 \sim 100$ & $100 \sim 300$ & $>300$ \\
\hline Village density $/ \mathrm{km}^{2}$ & $<0.2$ & $0.2 \sim 0.3$ & $0.3 \sim 0.4$ & $>0.4$ \\
\hline Total agricultural output value $/ 10^{4}$ yuan $/ \mathrm{km}^{2}$ & $<1$ & $1 \sim 10$ & $10 \sim 20$ & $>20$ \\
\hline Total industrial output value $/ 10^{4}$ yuan $/ \mathrm{km}^{2}$ & $<10$ & $10 \sim 30$ & $30 \sim 100$ & $>100$ \\
\hline Total posts and telecommunications service & $<0.1$ & $0.1 \sim 0.5$ & $0.5 \sim 1.0$ & $>1.0$ \\
amounts $/ 10^{4}$ yuan $/ \mathrm{km}^{2}$ & $<0.1$ & $0.1 \sim 0.3$ & $0.3 \sim 0.6$ & $>0.6$ \\
\hline Cultivated area percentage $/ \%$ & $<100$ & $100 \sim 1000$ & $1000 \sim 2000$ & $>2000$ \\
\hline Houses density $/ \mathrm{km}^{2}$ & $<0.1$ & $0.1 \sim 0.2$ & $0.2 \sim 0.5$ & $>0.5$ \\
\hline Roads density $/ \mathrm{km}^{2}$ & $<0.001$ & $0.001 \sim 0.02$ & $0.02 \sim 0.05$ & $>0.05$ \\
\hline Railways density $/ \mathrm{km}^{2}$ & $<0.25$ & $0.20 \sim 0.50$ & $0.50 \sim 0.75$ & $>0.75$ \\
\hline Electric and communication line density $/ \mathrm{km}^{2}$ & No & county & city & nation \\
\hline Grade of historical sites and scenic areas & 1 & 3 & 6 & 10 \\
\hline Grade value & & 6 & \\
\hline
\end{tabular}

Determination of the weight. The influence of each index is different. To reflect the gradation between indexes and make the solution feasible, the weight of each index can be calculated by gradation method. The weight vector is $R=\left(R_{1}, R_{2}, \ldots, R_{11}\right)=(0.392,0.065,0.059,0.071,0.049$, $0.034,0.036,0.080,0.130,0.034,0.050)$.

Analysis of resistance ability in disaster area. Resistance ability in disaster area is the ability of fighting against a disaster or lightening loss. It mainly includes the four aspects:

Ability of managing disaster: According to the rounded level, expression of running the laws and coordination efficiency of hazard resistant organization, the ability can be divided to low, medium and high degree. The value of each degree is $0.03,0.02$ and 0.01 .

Level of forecasting a disaster: According to the rounded level, facility performance, and performance of forecasting system of the forecasting organization, the level can be divided to low, medium and high degree. The value is $0.03,0.02$ and 0.01 .

Methods of fighting against a disaster: According to whether there is a fighting method, advanced level and effectiveness of the method, the level can be divided to low, medium and high degree. The value is $0.03,0.02$ and 0.01 .

Ability of constructions fighting against the disaster:This ability is more influent to the evaluation result. Because the surveying of constructions is complex, According to the building time and structure of constructions, the level can be divided to low, medium and high degree. The value is $0.03,0.02$ and 0.01 .

Ability of an area fighting against the collapse disaster is evaluated by the comprehensive analysis of the above indexes. According to the forecasting and regulating situation of local government, the risk degree is the sum of each index's degree. Lightening efficiency reflects the ability of regulating disaster of an area. The ability gets bigger as the efficiency gets bigger. Relation of the sum of risk degree and lightening efficiency is shown in table 4.

Table 4 Relation of sum of risk degree and lightening efficiency

\begin{tabular}{llll}
\hline Sum of risk degree & $<0.05$ & $0.05 \sim 0.1$ & $>0.1$ \\
\hline Lightening efficiency & $0.2 \sim 0.1$ & $0.1 \sim 0$ & 0 \\
\hline
\end{tabular}

Calculation methods and classification of vulnerability. The vulnerability degree is expressed by vulnerability exponent. The loss of the disaster gets bigger as the exponent gets bigger. The vulnerability exponent is calculated by:

$$
Y_{i}=\left(1-f_{z}\right) \sum_{j=1}^{m} R(j) \cdot X(i, j)
$$

In eqn.2: $Y_{i}$ is the vulnerability exponent of each element; $f_{z}$ is the lightening efficiency, which is 
valued by ability of fighting against the disaster; $R(j)$ is weight of each index; $X(i, j)$ is the value of each index.

The classification standards of vulnerability are shown in table 5 .

Table 5 Vulnerability grading standards

\begin{tabular}{lllll}
\hline Vulnerability Grade & Low (I) & Medium (II) & Less high (III) & High (IV) \\
\hline Vulnerability exponent & $<2.5$ & $2.5 \sim 4$ & $4 \sim 5.5$ & $\geq 5.5$ \\
\hline
\end{tabular}

\section{Calculation of risk exponent}

Risk evaluation of mining collapse in Beijing is based on the hazard evaluation and vulnerability evaluation. Risk exponent is used to reflect the risk degree. The risk gets bigger as the exponent gets bigger. The equation of calculating the risk exponent is expressed as: $F=W \times Y$. $F$ is risk exponent; $W$ is hazard exponent; $Y$ is vulnerability exponent. The classification standards of the risk are shown in table 6 .

Table 6 Risk grading standards

\begin{tabular}{lllll}
\hline Risk grade & Low risk & Medium risk & Less high risk & High risk \\
\hline Risk exponent & $<7$ & $7 \sim 17$ & $17 \sim 27$ & $>27$ \\
\hline
\end{tabular}

\section{Example analysis}

Mentougou region is located in the southwest mountains, Beijing, its area is $1455 \mathrm{~km}^{2}$. Mining history of this region is long. There are thousands of current kilns, stopping kilns and ancient kilns in the region. Mining land collapse disaster is the most serious in Beijing[4]. The map of Mentougou region is divided to 1455 elements. According to the surveying data, the parameters of each element are extracted. Then the risk exponents of each element can be calculated and classified by above the methods. The zoning map of the land collapse risk in Mentougou region is shown in Figure 1. The results calculated by this paper are almost the same as the actual situation and can be a foundation of the controlling work in this area. The method can be taken as an example for evaluation work in other The mining area.

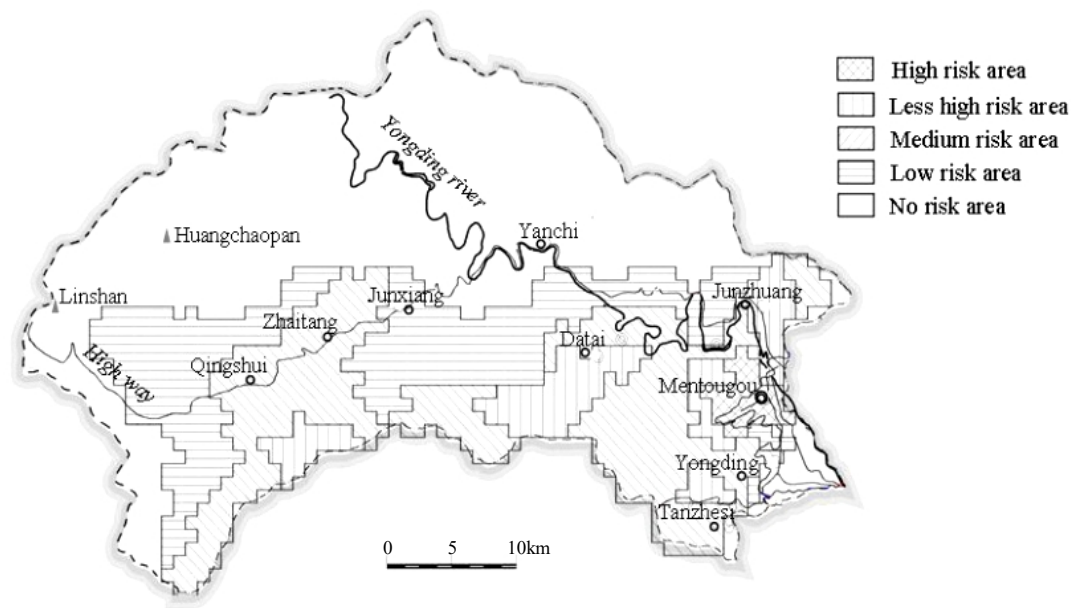

Figure 1 The risk map of mining land collapse in Mentougou region

\section{References}

[1] Yecheng Zhang \& Liang Zhang, Geological Hazards and Environment, Vol.7(3),pp1-6, 1999

[2] Xingang Wang, Longjv Zhang, Xiaola Feng, Safety and Environmental Engineering, Vol.18(2), pp18-21, 2011

[3] Ma Yan-sheng \& Zhang Ye-cheng, Journal of Geomechanics, Vol.10(1), pp.7-16, 2004 
[4] Beijing institute of geology, Report of geological disasters investigation in Beijing, 2013 